\title{
Acute renal failure due to membranoproliferative glomerulonephritis and kidney tumoral infiltration in a patient with mantle cell lymphoma
}

\begin{abstract}
Mantle cell lymphoma (MCL) is a subtype of non-Hodgkin lymphoma (NHL) that usually presents with a disseminated disease at diagnosis. In spite that multiple extranodal sites are frequently involved, the kidney is rarely affected in MCL. In NHLs, kidney is usually involved due to direct Tumoral infiltration or to the development of Glomerulonephritis, being Membranoproliferative Glomerulonephritis (MPGN) the most common cause. Herein, we report a patient with MCL who presented at diagnosis with an acute renal failure, haematuria, and nephritic syndrome due to both MPGN and Tumoral infiltration. To our knowledge, the association between MCL with both Tumoral cell infiltration and MPGN has not been reported before. Both renal function andhaematuriaimproved after the administration of immunochemotherapyadministration for the MCL.
\end{abstract}

Keywords: non-hodgkin lymphoma, mantle cell lymphoma, proteinuria, haematuria, membranoproliferative glomerulonephritis
Volume I Issue I - 2015

\author{
Julia Montoro,' Elías Jatem, ${ }^{2}$ Pau Abrisqueta,' \\ Nerea Castillo,' Sabela Bobillo,' María Teresa \\ Salcedo, ${ }^{3}$ JosepaVila, ${ }^{2}$ Francesc Bosch' \\ 'Department of Hematology, University Hospital Vall d' Hebron, \\ Spain \\ 'Department of Nephrology, University Hospital Vall d' Hebron, \\ Spain \\ ${ }^{3}$ Department of Pathology, University Hospital Vall d' Hebron, \\ Spain
}

Correspondence: Julia Montoro, University Hospital Vall d' Hebron, Paseo Vall de hebron II 9, Barcelona, Spain, Tel 686046920, Email juliamontorogomez@gmail.com

Received: February 20, 2015 | Published: April 02, 2015
Abbreviations: MCL, mantle cell lymphoma; NHL, non-hodgkin lymphomas, MPGN, membranoproliferative glomerulonephritis

\section{Introduction}

Mantle cell lymphoma (MCL)represents 5-10\% of all B-cell nonHodgkin lymphomas (NHL) and is characterized by the proliferation of mature B-lymphocytes, usually co expressing CD5, that infiltrate lymphoid tissues, bone marrow, peripheral blood, and extranodal sites. ${ }^{1}$ Genetically, MCL is characterized by the $\mathrm{t}(11 ; 14)(\mathrm{q} 13 ; 32)$ translocation which leads to the rearrangement and over expression of the cyclin D1 gene. ${ }^{2,3}$ From the clinical standpoint, MCL usually has an aggressive clinical course with short responses to treatment, frequent relapses, and short survival. ${ }^{4}$

MCL is usually diagnosed at advanced stages with frequent extranodal infiltration, including peripheral blood and bone marrow, gastrointestinal tract or Waldeyer's ring involvement. ${ }^{4}$ In contrast, urinary tract involvement in MCL is exceedingly rare. Thus, only few cases of MCL with acute renal failure, renal function impairement, and ornephrotic syndrome have been previously reported. ${ }^{5}$ In this sense, although Membranoproliferative Glomerulonephritis (MPGN) has been communicated to occur in association with lymphoproliferative disorders, only few cases of MPGN with nephritic syndrome related to MCL have been published so far. Herein we reported a patient diagnosed with MCL who developed acute kidney injury due to both MPGN and Tumoral lymphoid infiltration of the kidneys. The pathogenesis of these complications and their clinical implications are analyzed.

\section{Case report}

A 65 years-old male was diagnosed with a classic variant of MCL and referred to our institution for disease assessment and treatment. Past medical history included hypertension that was properly controlled by receiving ACE inhibitors. The patient presented with night sweats, weight loss superior to $10 \%$, and mild fatigue that started ten months before the diagnosis. Physical examination disclosed tonsil, liver, and spleen enlargements. Initial laboratory tests showed $\mathrm{Hb} 84 \mathrm{~g} / \mathrm{L}, \mathrm{MCV}$ $97 \mathrm{fL}, \mathrm{WBC}$ count of $48.3 \times 10^{9} / \mathrm{L}$ with $22.7 \times 10^{9} / \mathrm{L}$ lymphocytes, and platelet count of $112 \times 10^{9} / \mathrm{L}$. Serum creatinine and urea were of $2.8 \mathrm{mg} /$ $\mathrm{dl}$ and $94 \mathrm{mg} / \mathrm{dL}$, respectively, total serum protein was $74 \mathrm{~g} / \mathrm{L}$, potassium was of $6.4 \mathrm{mmol} / \mathrm{l}$, and LDH serum was of $415 \mathrm{UI} / \mathrm{L}(\mathrm{nv}<400 \mathrm{U} / \mathrm{L})$. The 24-hour urinary volume was $4300 \mathrm{~mL}$ and total proteinuria was of $2,038 \mathrm{mg} / 24 \mathrm{hours}$. Serum and urine protein electrophoresis did not revealed monoclonal component. Viral serological test were negative for HBV, HCV, HIV 1 and 2. Microscopic examination of a tonsil biopsy showed a lymphoid infiltration composed by small and medium centrocyte-like cells that were CD20+, CD5+, and cyclin D1+. The Ki 67 expression was of $20 \%$. Cytogenetic analysis of bone marrow showed a complex karyotype $\{[43-44, X Y,-11, \operatorname{der}(14), \mathrm{t}(11 ; 14)$ (q13;q32),-15, der(20),t(1;20)(q24;q13.3)[7]\}. Bone marrow biopsy and colon biopsy disclosed infiltration by Tumoral lymphoid cells with characteristics of MCL. Flow cytometry study of peripheral blood showed $82 \%$ of lymphocytes with MCL characteristic phenotype. Finally, PET-CT revealed multiple increased metabolic activity in several lymphoid areas, liver and spleen. Abdominal ultrasonography showed an enlarged liver of $19 \mathrm{~cm}$ and normal sized kidneys with increased echogenicity and multiple bilateral cysts. Altogether, the diagnosis of MCL, classical variant, stage IV-B was established.

According to local guidelines, treatment with EPOCH-R (rituximab $385 \mathrm{mg} / \mathrm{m}^{2}$ on day 1 , etoposide $103 \mathrm{mg} / \mathrm{m}^{2}$ on days $1-4$, prednisone $130 \mathrm{mg} / \mathrm{m}^{2}$ on days $1-5$, vincristine $0.6 \mathrm{mg} / \mathrm{m}^{2}$ on days $1-4$, adriamycin $20 \mathrm{mg} / \mathrm{m}^{2}$ on days $1-4$ and cyclophosphamide $1,540 \mathrm{mg} /$ $\mathrm{m}^{2}$ on day 5 ), along with prophylaxis for Tumoral lysis syndrome were administered. On the fifth day after chemotherapy, the patient developed a renal function impairment with macroscopic haematuria 
containing dysmorphic erythrocytes, increase of serum creatinine, and proteinuria up to $6.37 \mathrm{mg} / \mathrm{dl}$ and to $3.5 \mathrm{~g} / 24$ hours, respectively. Serum phosphates, calcium uric acid, fibrinogen, and coagulation tests were normal. Thrombosis of the renal vein or extrinsic compression by lymphadenopathy were rule out by renal ultrasonography. Flow cytometry analysis of the urine sample disclosed the presence of clonal lymphocytes with MCL phenotype. The transjugular renal

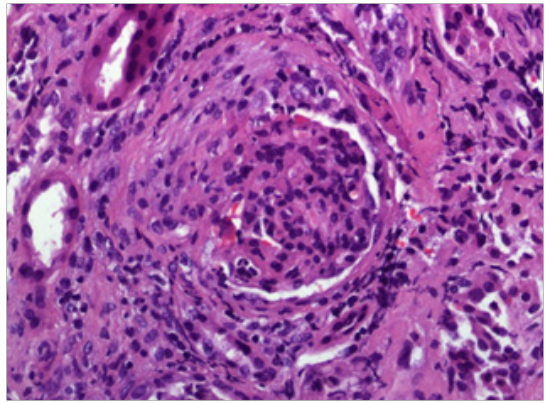

biopsy examination showed mesangialhypercelullarity, thickening of capillary basal membranes, some fibrocelullar crescents (Figure 1A); moderate intimal fibrous thickening of medium and small caliber arterioles (Figure 1B); and focal intersticial infiltration by atypical lymphoid B cells cyclin D1 positive (Figure 2). The tonsil biopsy showed positive immunohistochemical staining of the cycline D1 (Figure 3).

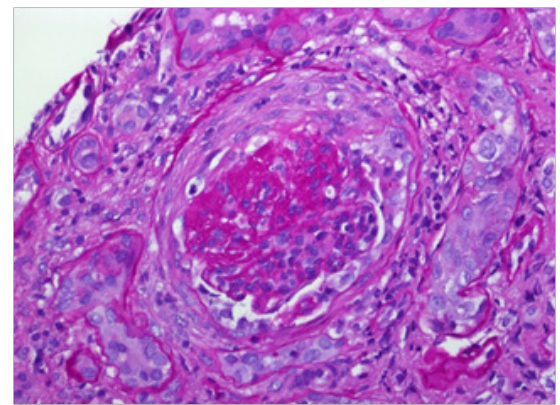

Figure I (A) Mesangial hypercelullarity, thickening of capillary basal membranes, some fibrocellular crescents (B) Moderate intimal fibrous thickening of medium and small caliber arterioles.

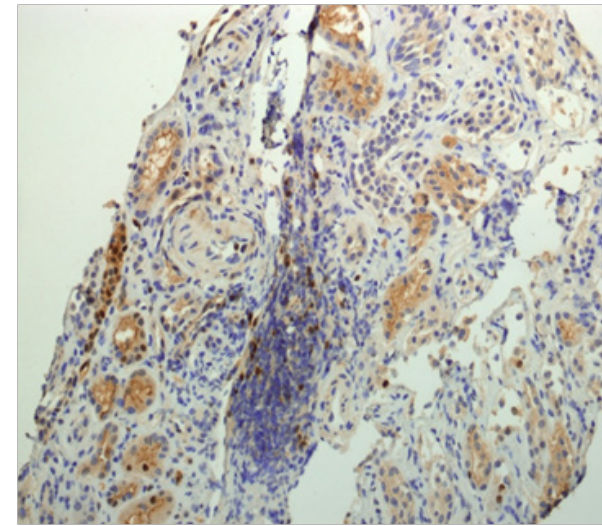

Figure 2 Focal intersticial infiltration by atypical lymphoid cells cycline DI positive in the renal biopsy.

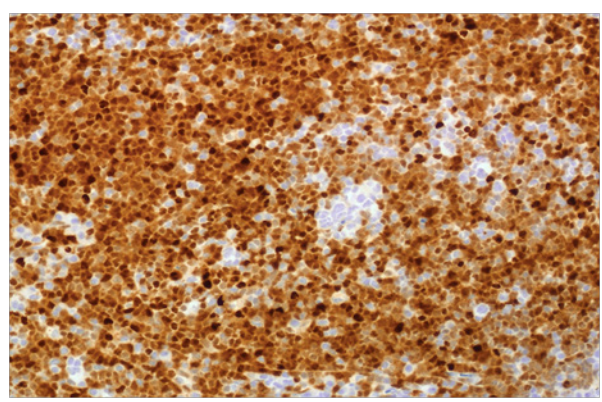

Figure 3 Positive inmunohistochemical staining of the cycline DI of the tonsil biopsy.

With all these findings, the concomitant diagnosis of both MPGN and kidney infiltration by MCL was performed. The patient was subsequently treated with high doses of intravenous metilprednisolone $(1 \mathrm{mg} / \mathrm{Kg} /$ day $)$.One week later, creatinine serum levels diminished to $2.4 \mathrm{mg} / \mathrm{dl}$ and haematuria resolved. One month after the first course of chemotherapy, peripheral blood lymphocyte count and serum creatinine rose up to the values observed at diagnosis, this being considered as an inadequate response to the therapy. For these reasons, the patient started salvage therapy with R-HAD-B regimen (rituximab $388 \mathrm{mg} / \mathrm{m}^{2}$ on day 1 and 2 , bortezomid $3,08 \mathrm{mg} / \mathrm{m}^{2}$ on day 2 and 5 , citarabine $1540 \mathrm{mg} / \mathrm{m}^{2}$ on day 3 and dexamethasone $40 \mathrm{mg} / \mathrm{m}^{2}$ on day 2 to 5). After four courses of such treatment the patient was considered in complete response. Moreover, serum creatinine diminished to $1.77 \mathrm{mg}$ / $\mathrm{dL}$, and the haematuria and proteinuria disappeared. Two months after the end of chemotherapy, the patient underwent autologous stem-cell progenitor transplant that was uneventful. Two years later the patient is still in complete remission and the renal function remains normal.

\section{Discussion}

Herein, we report a patient diagnosed with MCL that developed renal insufficiency due to both kidney Tumoral infiltration and MPGN. Renal function impairment in patients with lymphoma can be due to direct causes, like tumor infiltration or ureteral obstruction, or to indirect effects such as hypercalcemia, tumor lysis syndrome, tubular obstruction by light-chain precipitation, and treatmentrelated effects. ${ }^{6}$ In addition to that, widespread tumour infiltration of the kidney has been reported in almost one-third of the autopsies in patients with lymphoma ${ }^{7}$ although acute renal failure due to bilateral infiltration of the kidneys is unusual and is rarely the presenting sign of a lymphoid malignancy. ${ }^{8,9}$ In our patient a direct infiltration of the kidney by lymphoid Tumoral cells with characteristics of MCL was observed. Regardless of the fact that MCL is generally diagnosed in advance stage with frequent extranodal involvement, direct Tumoral infiltration of the kidney by MCL is exceedingly rare, with few cases being reported until now. ${ }^{10,11}$ Paraneoplasticglomerulonephritishas been associated with carcinoma of the lung or the gastrointestinal tract and with Hodgkin's lymphoma. Few cases of MPGN in patients with NHL have been described. ${ }^{12}$ MCL is rarely associated with MPGN, with only 4 cases published so far. ${ }^{13-15}$ The physiopathology of MPGN in the context of lymphoma is not well known. Chronic HCV infection is the most common cause of secondary MPGN and is often associated with cryoglobulinemia. Although $\mathrm{HCV}$ serology was negative in our patient, any condition associated with persistent immunological stimulation can result in secondary cryoglobulinemia. ${ }^{16,17}$ In our patient, although serum paraprotein were no detected in the laboratory tests, cryoglobulins were not directly measured and thus they cannot be excluded as a pathogenic mechanism. ${ }^{18,19}$

From the therapeutic standpoint, treatment of secondary MPGN associated with lymphoma requires both the symptomatic treatment of 
nephrotic syndrome and the treatment of the predisposing hematologic disorder. Of note, the remission of lymphoma parallels remission of the glomerulopathy, likewise the relapses. ${ }^{13}$ Therefore, the appearance of findings that suggest recurrence of Glomerulonephritis, should induce a work up for lymphoma relapse and vice-versa. ${ }^{20}$ According to the case herein reported, the development of renal impairment in patients with MCL should prompt physicians to exclude direct Tumoral infiltration or glomerulopathy, as these diagnoses have critical implications for the treatment and follow-up of these patient.

\section{Acknowledgements}

None.

\section{Conflict of interest}

The author declares no conflict of interest.

\section{References}

1. Swerdlow S, Campo E, Harris N, et al. World health organization (WHO) Classification of tumours of haematopoietic and lymphoid tissues. 4th ed. WHO; 2008.

2. Jares P, Colomer D, Campo E. Geneticand molecular pathogenesis of mantle cell lymphoma: perspectives for new targeted therapeutics. Nat Rev Cancer. 2007;7(10):750-762.

3. Bosch F, Jares P, Campo E, et al. PRAD-1/cyclin D1 gene over expression in chronic lymphoproliferative disorders: a highly specific marker of mantle cell. Blood. 1994;84(8):2726-2732.

4. Bosch F, López-Guillermo A, Campo E, et al. Mantle cell lymphoma: presenting features, response to therapy, and prognostic factors. Cancer. 1998;82(3):567-575

5. Schniederjan SD, Osunkoya AO. Lymphoid neoplasms of the urinary tract and male genital organs: a clinicopathological study of 40 cases. Mod Pathol. 2009;22(8):1057-1065.

6. Monfared A, Orangpoor RO, Fakheri TF, et al. Acute renal failure and bilateral kidney infiltration as the fisrt presentation of non-hodking lymphoma. Iran J Kidney Dis. 2009;3(1):50-53.

7. Obrador GT, Price B, O'Meara Y, et al. Acute renal failure due to lymphomatous infiltration of the kidneys. J Am Soc Nephrol. 8(8): 13481354.

8. Pras M, Franklin EC, Shibolet S, Frangione B (1992) Amyloidosis associated with renal cell carcinoma of the AA type. Am J Med. 1997; 73(3):426-428.
9. Chin KC, Perry GJ, Dowling JP, et al. Primary T-cell-rich-cell lymphoma in the kidney presenting with acute renal failure and a second malignancy. Pathology. 1999;31(4):325-327.

10. Davies J, Healey DA, Wood KM, et al. Acute renal failure due to mantle cell lymphoma-a case report and discussion of the literature. Clin Nephrol. 2007;67(6):394-396.

11. Colak N, Dede F, Canbakan B, et al. Acute tubulo-interstitial nephritis associated with mantle cell lymphoma presented as acute renal failure. Nephrology. 2007;12(1):107-110.

12. Rault R1, Holley JL, Banner BF, et al. Glomerulonephritis and nonHodkin's lymphoma: a report of two casses and review of the literature. Am J Kidney Dis. 1992;20(1):84-89.

13. Karim M, Hill P, Pillai G, et al. Proliferative Glomerulonephritis associated with mantle cell lymphoma-natural history and effect of treatment in 2 cases. Clin Nephrol. 2004;61(6):422-428.

14. Da'as N, Polliack A, Cohen Y, et al. Kidney involvement and renal manifestations in non-Hodking's lymphoma and lymphocytic leukemia: a retrospective study in 700 patients. Eur J Hematol. 2001;67(3):158164.

15. Rerolle JP, Thervet E, Beaufils H, et al. Crescentic Glomerulonephritis and centrocytic lymphoma. Nephrol Dial Transplant. 1999;14(7):1744 1745 .

16. Rosas SE, Tomaszewski JE, Feldman HI, et al. Membranoproliferativeglomerulonphritis type I, mixed cryoglobulinemia and lymphoma in the absence of hepatitis C infection. Am J Nephrol. 1999;19(5):599-604.

17. Smith KD, Alpers CE. Pathogenic mechanisms in Membranoproliferative Glomerulonephritis. Curr Opin Nephrol Hypertens. 2005;14(4):396403

18. Korbert SM, Schwartz MM, Lewis EJ. Immunotactoidglomerulopathy. Am J Kidney Dis. 1991;17(3):247-257.

19. Alpers CE, Rennke HG, Hopper J Jr, et al. Fibrillary Glomerulonephritis: An entity with unusual immunfluorescence features. Kidney Int. 1987;31(3):781-789.

20. Hala Alshayeb, Barry M. Wall corresponding Non Hodkin's Lymphomas associated Membranoproliferative Glomerulonephritis: rare case report of long term remission with chemotherapy: a case report. Cases J. 2009;2:7201 